\title{
As bandas marciais escolares como espaços de inclusão social da juventude
}

\section{brasileira}

\author{
School martial bands as spaces of social inclusion for brazilian youth \\ Las bandas marciales escolares como espacios de inclusión social de la juventude brasileña
}

Recebido: 12/02/2021 | Revisado: 16/02/2021 | Aceito: 20/02/2021 | Publicado: 28/02/2021

Rafael de Souza Velasco
ORCID: https://orcid.org/0000-0002-3715-9061
Instituto Federal de Educação, Ciência e Tecnologia Sul-rio-grandense, Brasil
E-mail: rafaelvelasco_rs@yahoo.com.br
Rafael Montoito
ORCID: https://orcid.org/0000-0002-3294-3711
Instituto Federal de Educação, Ciência e Tecnologia Sul-rio-grandense, Brasil
E-mail: xmontoito@gmail.com
Diogo Franco Rios
ORCID: https://orcid.org/0000-0001-8391-5721
Universidade Federal de Pelotas, Brasil
E-mail: diogofrancorios@gmail.com

\section{Resumo}

Este artigo revisita a dissertação Recordações em pauta: uma narrativa sobre a banda marcial da Escola Técnica Federal de Pelotas (ETFPEL) entre as décadas de 60 e 70, cotejando os trabalhos comentados em seu Estado do Conhecimento e as entrevistas dadas por ex-membros da referida banda, que integram a dissertação na forma de anexo. Se, num primeiro momento, enquanto a pesquisa era realizada, o Estado do Conhecimento serviu para que o pesquisador adentrasse ao tema das bandas marciais escolares, a fim de construir um referencial teórico e metodológico para sua pesquisa, aqui se produz, dele, uma síntese na forma de categorias, as quais podem ser tomadas como representativas das pesquisas sobre bandas marciais escolares; essas categorias são cotejadas, posteriormente, com as entrevistas dos ex-alunos, ex-membros da Banda ETFPEL, visando produzir interpretações e aproximações entre as temáticas, de modo a compreender algumas das experiências que as bandas suscitavam em seus integrantes. $\mathrm{O}$ resultado da análise revela que, independentemente da regionalização e das diferenças intrínsecas a cada comunidade escolar, os ex-alunos das bandas reconhecem a experiência de tomar parte nelas como sendo promotora de espaços de inclusão e de aprendizagem, tanto musical quanto cidadã.

Palavras-chave: Banda marcial; Ensino musical; Comunidade escolar; Ensino.

\begin{abstract}
This article revisits the dissertation entitled Memories on the agenda: a narrative about the martial band of the Escola Técnica Federal de Pelotas (ETFPEL) in the 60s and 70s (Recordações em pauta: uma narrativa sobre a banda martial da Escola Técnica Federal de Pelotas (ETFPEL) in the 60s and 70s), comparing the works discussed in its State of Knowledge and the interviews given by former members of the referred band, which integrate the dissertation as an appendix. If, at first, while the research was being carried out, the State of Knowledge was useful for the researcher to enter into the theme of school martial bands in order to build a theoretical and methodological reference for his research, here a synthesis is produced from it in the form of categories, which can be taken as representative of research on school martial bands; these categories are compared, later, with the former students interviews which are former members of the ETFPEL Band, aiming to produce interpretations and approximations between the themes, in order to understand some of the experiences that the bands aroused in their members. The result of the analysis reveals that, regardless of regionalization and the differences intrinsic to each school community, the former bands' students recognize the experience of taking part in them as promoting spaces of inclusion and learning, both musically and as citizens.
\end{abstract}

Keywords: Marcial band; Music education; School community; Teaching.

\section{Resumen}

Este artículo revisita la tesis Memorias en la agenda: una narrativa sobre la banda marcial de la Escuela Técnica Federal de Pelotas (ETFPEL) entre los años 60 y 70, cotejando los trabajos comentados en su Estado del Conocimiento y las entrevistas dadas por ex miembros de dicha banda, que integran la tesis en forma de anexo. Si, en un primer momento, mientras se realizaba la investigación, el Estado del Conocimiento sirvió para que el investigador se adentrara en el tema de las bandas marciales escolares, con el fin de construir un marco teórico y metodológico 
para su investigación, aquí se produce una síntesis, en forma de categorías, las cuales pueden ser tomadas como representativas de las investigaciones sobre bandas marciales escolares; estas categorías luego se comparan con las entrevistas de ex alumnos, ex integrantes de la Banda ETFPEL, buscando producir interpretaciones y aproximaciones entre las temáticas, de modo a comprender algunas de las experiencias que las bandas suscitaban en sus integrantes. El resultado del análisis muestra que, independientemente de la regionalización y de las diferencias intrínsecas a cada comunidad escolar, los ex alumnos de las bandas reconocen la experiencia de tomar parte en ellas como promotora de espacios de inclusión y aprendizaje, tanto musical como ciudadana.

Palabras clave: Banda marcial; Enseñanza musical; Comunidad escolar; Ensenãnza.

\section{Introdução}

Este artigo revisita uma dissertação que se propôs a construir uma história da Banda Marcial da antiga ETFPEL $^{1}$ a partir de entrevistas com seus ex-integrantes, visando entender melhor as relações que esses estabeleciam com a Banda, com a música e com a instituição num tempo histórico selecionado - entre as décadas de 60 e 70.

$\mathrm{O}$ artigo aqui apresentado, com características de uma investigação qualitativa e bibliográfica, revisita o Estado do Conhecimento da dissertação referida à procura de novos significados e interpretações, num duplo movimento: num primeiro momento, os autores aprofundam as discussões dos trabalhos anteriormente selecionados e produzem, a partir deles, uma síntese, a qual é apresentada em dois fluxogramas que expõem as categorias que emergiram deste olhar mais acurado, sendo elas Relação entre Ensino e Aprendizagem e Motivação do Aluno; num segundo momento, cotejam essas categorias com as entrevistas transcritas para a dissertação, obtidas por meio da História Oral, buscando espaços de aproximação e de distanciamento, ensejando entender um pouco mais sobre a temática das bandas escolares, e não apenas sobre a Banda EFPEL, que era o cerne da dissertação.

Assim, entre o Estado do Conhecimento inicial (puramente descritivo) e a transcrição das entrevistas (cujas falas dos entrevistados serviram com uma das fontes de pesquisa para que fosse possível escrever uma historiografia da Banda ETFPEL), considera-se agora um espaço de novos estudos, cujos resultados expressos vão além daqueles que satisfaziam os objetivos enunciados na dissertação de Velasco (2019).

\section{A Elaboração de Categorias a Partir da Revisitação ao Estado do Conhecimento}

Para Ferreira (2002, p. 257), as pesquisas do tipo "Estado do Conhecimento" seriam pesquisas bibliográficas que visam "mapear e discutir certa área de produção acadêmica em diferentes campos do conhecimento". Elas utilizam alguns princípios metodológicos de caráter inventariante, mas priorizam a perspectiva descritiva da produção acadêmica e permitem a liberdade de opção na definição do objeto de análise, tais como dados bibliográficos e/ou resumos, por exemplo. Os dados podem ser obtidos em banco de dados ou catálogos e a elaboração de um catálogo pode ser o próprio objetivo do estudo - o que, ressaltamos desde já, não foi o caso da dissertação elaborada.

Lehfeld (1991) refere-se à pesquisa como sendo a inquisição, o procedimento sistemático e intensivo, que tem por objetivo construir conhecimentos e interpretar os fatos que estão inseridos em uma determinada realidade. Pesquisadores como Gunther (2006) e Pereira et al. (2018), dentre outros, dispõem que a pesquisa qualitativa estuda um determinado fenômeno no seu contexto natural, implicando relativa falta de controle de variáveis estranhas, entendendo que não existem variáveis interferentes ou irrelevantes, pois todas as variáveis do contexto são consideradas importantes. Observa-se também que a pesquisa qualitativa, tal como a de Velasco (2019) que aqui se revisita para produzir novas análises, não é isenta do olhar do observador, ou seja, o olhar do pesquisador já é uma espécie de filtro no processo de interpretação da realidade com a qual se

\footnotetext{
${ }^{1}$ Abreviatura para Escola Técnica Federal de Pelotas; podendo ser encontrada neste texto como ETP (Escola Técnica de Pelotas), Escola Técnica ou até mesmo Escola, como é trivialmente conhecida pela comunidade Pelotense. Importante salientar que sempre se trata da mesma instituição e, ainda, que após passar por diversas mudanças de nome, hoje é conhecida como Instituto Federal de Educação, Ciência e Tecnologia Sul-rio-grandense (IFSul).
} 
defronta. Esse filtro está associado à própria bagagem cultural dos pesquisadores. O conhecimento, experiências e teorias do pesquisador são construídos como uma interpretação da realidade, uma vez que

[...] a pesquisa qualitativa é a atividade investigativa que posiciona o observador no mundo, ela consiste em um conjunto de práticas interpretativas e materiais que tornam o mundo visível. Neste contexto, a pesquisa qualitativa envolve um caráter interpretativo e de abordagem naturalística diante do mundo, ou seja, os pesquisadores estudam as coisas em seus contextos naturais, procurando compreender e/ou interpretar os fenômenos em termos dos sentidos que as pessoas the atribuem (Flick, 2009, p. 33).

Segundo Teixeira (2017, p. 41), a vantagem de usar esse método do Estado do Conhecimento encontra-se "no desafio de conhecer o já constituído e produzido para depois buscar o que ainda não foi feito", mas também de divulgar o saber que se avoluma cada vez mais rapidamente nas universidades, banco de dados, catálogos. O Estado do Conhecimento traz o desafio de mapear e discutir temas de produções acadêmicas em diferentes campos, motivo pelo qual é considerado uma das partes mais importantes de um trabalho científico, uma vez que possibilita nos aprofundarmos em conhecimentos que já foram estudados. O Estado do Conhecimento tem o papel de coletar o maior número possível de informações relevantes sobre o assunto que se pretende estudar.

Sendo assim, no começo de sua pesquisa, Velasco (2019) realizou um estudo exploratório, investigando o que já havia sido produzido sobre a temática de Bandas Marciais, na expectativa de que este primeiro movimento de pesquisa instrumentalizasse o então mestrando para, posteriormente, dirigir seu olhar à Banda ETFPEL, ajudando na delimitação de teorias e metodologias que poderiam vir a ser mobilizadas no restante da sua pesquisa.

Aqui, esse Estado de Conhecimento é um novo ponto de partida que (quase) configura um novo Estado do Conhecimento pois, na produção de interpretações, junta-se às pesquisas encontradas a própria pesquisa de Velasco (2019); a este grupo novo de material, dirige-se um outro olhar, sobretudo a partir das transcrições das entrevistas de seus colaboradores de pesquisa, ex-membros da Banda ETFPEL, no ensejo de entender um pouco mais sobre a temática das bandas escolares.

O Estado do Conhecimento da dissertação foi produzido utilizando-se de diferentes bases de dados como fonte de busca, dentre elas a Biblioteca Digital Brasileira de Teses e Dissertações (BDTD), Instituto Brasileiro de Informação em Ciência e Tecnologia (IBICT) e o Banco de Teses da Coordenação de Aperfeiçoamento de Pessoal de Nível Superior (CAPES). Alguns repositórios também foram consultados, como o Scientific Electronic Library Online (SciELO), assim como o de diversas universidades renomadas do Brasil: Universidade Federal do Rio Grande do Sul (LUME), Universidade Federal de Santa Maria (UFSM), Universidade Federal do Paraná (UFPR), Universidade Federal de Santa Catarina (UFSC) e Universidade de São Paulo (USP).

Foi utilizado um filtro para a realização da pesquisa, com as palavras-chaves Banda Marcial; Educação. Foram encontrados, como resultado, 4 trabalhos no total, sendo 3 dissertações e 1 tese, entre os anos de 2010 até 2017, o que se pode ver no quadro a seguir: 
Quadro 1 - Pesquisas encontradas na elaboração do Estado do Conhecimento.

\begin{tabular}{|c|c|c|c|c|c|c|c|c|c|}
\hline Palavras-chave: & \multicolumn{8}{|c|}{ Ano } & \multirow[b]{2}{*}{ Total } \\
\hline Banda Marcial; Educação. & 2010 & 2011 & 2012 & 2013 & 2014 & 2015 & 2016 & 2017 & \\
\hline Dissertações & 1 & - & 1 & - & 1 & - & - & - & 3 \\
\hline Teses & - & - & - & - & - & - & - & 1 & 1 \\
\hline Total Geral & 1 & 0 & 1 & 0 & 1 & 0 & 0 & 1 & 4 \\
\hline
\end{tabular}

Fonte: Velasco (2019, p. 25).

O Quadro 1 mostra, a partir das palavras-chave escolhidas, que poucas pesquisas foram encontradas no tempo delimitado. O limitado número de trabalhos pode ser tomado como um indicador de que Banda Marcial e Educação, enquanto temáticas gerais para a realização de uma investigação, era, até então, uma articulação pouco explorada - ressalta-se, ainda, que nenhuma das pesquisas versava sobre a Banda ETFPEL, acenando a potencialidade investigativa do tema da dissertação que seria feita.

No Quadro a seguir, os dados principais de cada pesquisa aparecem registrados.

Quadro 2 - Dados principais das dissertações e tese encontradas na elaboração do Estado do Conhecimento.

\begin{tabular}{|c|c|c|c|c|}
\hline \multicolumn{2}{|c|}{ DISSERTAÇõES } \\
\hline $\begin{array}{c}\text { TÍTULO } \\
\text { ANO }\end{array}$ & AUTOR & LOCAL & $\begin{array}{c}\text { PALAVRAS- } \\
\text { CHAVE }\end{array}$ \\
\hline $\begin{array}{c}\text { "P'rá ver a banda passar": uma } \\
\text { etnografia musical da Banda } \\
\text { Marcial Castro Alves }\end{array}$ & 2010 & $\begin{array}{c}\text { Erihuus de Luna } \\
\text { Souza }\end{array}$ & $\begin{array}{c}\text { João } \\
\text { Pessoa/PB }\end{array}$ & $\begin{array}{c}\text { Banda Marcial; } \\
\text { etnomusicologia; } \\
\text { ensino e } \\
\text { aprendizagem } \\
\text { musical. }\end{array}$ \\
\hline $\begin{array}{c}\text { Banda Marcial Augusto dos } \\
\text { Anjos: processos de ensino- } \\
\text { aprendizagem musical } \\
\text { (dissertação) }\end{array}$ & 2012 & $\begin{array}{c}\text { Thallyana } \\
\text { Barbosa da } \\
\text { Silva }\end{array}$ & $\begin{array}{c}\text { João } \\
\text { Pessoa/PB }\end{array}$ & $\begin{array}{c}\text { Banda estudantil; } \\
\text { Banda Marcial } \\
\text { Augusto dos Anjos; } \\
\text { educação musical }\end{array}$ \\
\hline $\begin{array}{c}\text { Prática de banda em escolas de } \\
\text { ensino fundamental como } \\
\text { embasamento para processo } \\
\text { pedagógico: um estudo de caso } \\
\text { com duas escolas em } \\
\text { Guarulhos - SP } \\
\text { (dissertação) }\end{array}$ & 2014 & $\begin{array}{c}\text { Athus Rogério } \\
\text { Marconato }\end{array}$ & São Paulo/ SP & $\begin{array}{c}\text { Banda escolar; banda } \\
\text { marcial; fanfarra; } \\
\text { redes sociais; } \\
\text { abordagem centrada } \\
\text { na pessoa. }\end{array}$ \\
\hline $\begin{array}{c}\text { Saberes percussivos nas escolas } \\
\text { públicas da cidade de Fortaleza } \\
\text { (tese) }\end{array}$ & 2017 & $\begin{array}{c}\text { Catherine } \\
\text { Furtado dos } \\
\text { Santos }\end{array}$ & Fortaleza/CE & $\begin{array}{c}\text { Saberes percussivos; } \\
\text { escola pública; } \\
\text { maracatus; Banda } \\
\text { Marcial-Show. }\end{array}$ \\
\hline
\end{tabular}

Fonte: Velasco (2019, p. 29). 
Considerando o disposto no Quadro 2, passa-se agora à apresentação mais detalhada dos trabalhos encontrados na busca. Além dos comentários gerais, usuais num Estado do Conhecimento, serão trazidos excertos ${ }^{2}$ para que o leitor compreenda como foram identificados indícios que ajudaram a elaborar as duas categorias da síntese: "Relação entre Ensino e Aprendizagem" e "Motivação do Aluno". Comentários sobre elas perpassam toda esta seção e servirão para, de modo mais acurado, pensar o que cada uma traz em seu interior, como possíveis subcategorias.

A dissertação "P’rá Ver a Banda Passar: uma etnografia musical da Banda Marcial Castro Alves” (2010), de Erihuus de Luna Souza, teve como objetivo principal um estudo de caso etnomusicológico sobre a Banda Marcial Castro Alves. A abordagem teve como intuito contribuir com os estudos sobre bandas no país, buscando compreender o papel que esse tipo de educação musical desempenha em crianças e adolescentes nos espaços suburbanos, além de investigar as práticas, conhecimento musical e envolvimento da comunidade nessa corporação. Outro aspecto a ser destacado do trabalho é a descrição analítica dos aspectos gerais das músicas e da correlação delas com aspectos da performance e cultura em geral, ou seja, a música como forma de entretenimento e como fator de afirmação social.

A metodologia utilizada pelo autor incluiu pesquisa bibliográfica, pesquisa de campo e pesquisa de laboratório. A primeira etapa envolveu o levantamento bibliográfico e a consulta documental, que consistiu na consulta de documentos não publicados, arquivos públicos, acervos particulares e institucionais, documentos pessoais, dentre outros. Na pesquisa de campo, o pesquisador participou de atividades existentes na escola, coletando dados a partir da participação dos ensaios e apresentações da banda, almejando compreender aspectos particulares da música e suas inter-relações socioculturais.

$\mathrm{Na}$ pesquisa de laboratório, diante dos questionários escritos, entrevistas ou depoimentos orais, diário de campo, fotografia e gravações, o autor selecionou amostras relevantes das aulas, performances e entrevistas para serem transcritos ou editados para a etnografia, a partir de uma "descrição densa". A organização e análise de dados foram feitas a partir do referencial teórico, possibilitando reflexões tanto da realidade do espaço estudado quanto dos estudos da música em uma perspectiva etnomusicológica.

Quanto à "Relação entre Ensino e Aprendizagem" no ambiente da Banda Marcial, Souza (2010) destaca a maneira como se atribuía os instrumentos a cada integrante:

Já no primeiro ensaio (aula) os alunos de instrumentos de sopro têm contato com a escrita musical. Mais uma vez o regente conversa com o aluno, sondando o instrumento de sua preferência, para em seguida, indicar os instrumentos disponíveis ou os naipes que precisam ser completados. Caso a escolha do aluno coincida com a sugestão do maestro, o aluno vai imediatamente para a sala de aula já com o instrumento. Caso negativo, o regente tenta convencê-lo a aprender outro instrumento, prometendo que assim que tiver uma vaga no instrumento pretendido, ele poderá ser transferido. (Souza, 2010, p. 66).

Aqui a pesquisa relata a sensibilidade do Maestro ao conduzir o aluno ao instrumento mais adequado, considerando o interesse e vontade do aluno, mas também se utilizando de sua experiência para avaliar a melhor oportunidade para o futuro músico.

No caso exclusivo da aprendizagem dos instrumentos de sopro - chamados Metais -, o autor coloca o ambiente colaborativo das aulas, nas quais os alunos mais graduados, por tempo de Banda e por técnica apurada, atuam como instrutores. As explicações teóricas ficam por conta do Regente, que costuma iniciar suas aulas com explicações teóricas sobre as partes constitutivas dos instrumentos para, em seguida, conduzir a prática "de como respirar, como soprar, a posição correta dos lábios, a forma ideal de emissão sonora - sempre levando em conta as características técnicas singulares da banda, como a de segurar o instrumento em postura de desfile" (Souza, 2010, p. 67).

${ }^{2}$ Esses excertos caracterizam a revisita ao Estado do Conhecimento que, como já dito, na dissertação de Velasco (2019), era apenas descritivo. Este novo olhar, que exigiu dos autores do texto uma releitura dos trabalhos expressos no Quadro 2, é o que permitiu elaborar a síntese em categorias. 
Quanto à categoria "Motivação do Aluno", um dos pontos que as entrevistas realizadas nesse trabalho revelam com ênfase diz respeito aos interesses que teriam sido despertados nos jovens alunos ao decidirem participar da Banda da escola. O autor elencou, dentre as diversas razões, as respostas mais frequentes: “foi depois de ver uma apresentação'; 'um amigo [integrante da banda] теи mе trouxe aqui'; 'o prazer do aprendizado musical e do interesse em aprender um instrumento'; 'as viagens', ou a oportunidade de 'fazer novos amigos' e de 'conhecer outros lugares"' (Souza, 2010, p. 63).

Já o Maestro da Banda, quando entrevistado, contou que a grande motivação da juventude em fazer parte do projeto musical e o aumento da procura por ele se davam na proporcionalidade em que a Escola Castro Alves vencia os campeonatos, já que o mesmo entendia que na sociedade brasileira todos almejavam de alguma forma ocupar um "lugar social".

Outro entrevistado expôs um motivo especial para ingressar na Banda: "a preocupação de seus pais com o aumento do consumo de drogas entre os jovens no seu bairro, o que não exclui o prazer do aprendizado da música e a necessidade de ocupar o tempo ocioso desses jovens" (Souza, 2010, p. 64). A partir dessa fala, Souza (2019) acena para o possível papel de promotor de saúde mental que uma Banda pode representar na vida da juventude que a integra, já que, segundo o entrevistado, a dedicação ao aprendizado musical ocupa a rotina dos jovens com algo produtivo e gera satisfação pessoal ao evoluir com o conjunto.

A motivação do aluno ao pertencer ao espaço da Banda Marcial, enquanto mecanismo de formação de caráter, é abordado pelo Coordenador de Percussão e Coreógrafo da Banda Castro Alves: "Banda e conjunto todos têm que estar pensando juntos, assumimos um compromisso, todos no grupo têm sua importância e papel, se um levanta o pé todos têm que levantar, o grupo só é forte se caminhar unido com o mesmo ideal” (Dantas apud Souza, 2010, p. 67). Esse colaborador expressou diversas vezes que banda não se faz sem conjunto, levando o pesquisador a crer que isso fortalece a unidade dos integrantes com a ideia do todo, do fazer parte de algo maior que o sucesso individual, verdadeira lição prática de sociologia para os integrantes de uma agremiação, capaz de repercutir nos mais diversos aspectos de suas vidas.

A leitura dessa dissertação possibilitou pensar em como o processo de ensino-aprendizagem, quando misturado ao espaço de ações de uma Banda Marcial, exerce influência forte no comportamento disciplinar do estudante - questão essa que ressurge nas vozes dos entrevistados ex-membros da Banda ETFPEL.

A dissertação "Banda Marcial Augusto dos Anjos: processos de ensino-aprendizagem musical” (2012), de Thallyana Barbosa da Silva, teve como principal objetivo investigar os processos de ensino e aprendizagem da banda escolar que dá nome ao projeto, identificando a formação musical dos docentes e as condições da banda no que se refere ao espaço físico e instrumental. Visou ainda à observação do repertório e da metodologia de ensino que serviram para a análise da proposta pedagógica. A ideia da autora era compreender a função que a banda assume para a escola e investigar se o ensino de música contribuía para a profissionalização dos integrantes.

A metodologia utilizada para a obtenção dos resultados do estudo foi mista: entrevista de campo, observação das atividades da banda (aulas práticas e teóricas, apresentações, desfiles cívicos, ensaios etc), realização de questionários, entrevistas semiestruturadas e registros de vídeo. A fundamentação se deu por pesquisa bibliográfica, com base nas concepções e princípios da educação musical. Assim, foi possível que a autora constatasse que o ensino de música desenvolvido na banda da escola apresentava limitações que necessitavam ser superadas para garantir um ensino musical eficaz. Em contrapartida, a autora conclui que o ensino musical oferecido pela escola possibilitou significativas contribuições para a formação do estudante, ao promover o contato experiencial com a música e ao influenciar instrumentistas a seguirem carreira profissional na área musical.

Quanto à categoria elencada como "Relação entre Ensino e Aprendizagem", destaca-se como a autora relata a forma como eram as audições, a fỉm de que a direção da Banda pudesse escolher qual instrumento atribuiria ao jovem músico aprendiz, aluno da escola: 
Existem instrumentos na Banda que pesam 12 quilos, como por exemplo a Caixa. Há também o Bombo que tem peso aproximado de 8 quilos, e isso significa que não é possível qualquer aluno tocar. Às vezes, muitos alunos com peso e tamanho compatível aos instrumentos mais pesados desejam tocá-los, no entanto o regente procura adequá-los a outros instrumentos. Não há resistência por parte dos alunos, pois o importante para eles é participar da Banda (Silva, 2012, p. 94).

Já em relação à categoria "Motivação do Aluno" a autora saúda, entre outras colocações, o Projeto de Bandas da prefeitura de João Pessoa, na Paraíba. O referido projeto, segundo ela pontua, tem por finalidade principal que cada escola da rede municipal de ensino conte com uma banda, propiciando que a música sirva como ferramenta educacional que contribui na formação do aluno enquanto cidadão, bem como para contribuir com a redução da evasão escolar.

A dissertação de Silva (2012), por tratar de abordagens pedagógicas para se aproximar da juventude, ajudou Velasco (2019) a pensar tanto no processo de ensino e aprendizagem ao qual os alunos estavam inseridos, quanto na promoção social que a Banda ETFPEL lhes oferecia. A abordagem da autora, realizando entrevistas, preocupando-se com a importância do ensino musical para o desenvolvimento do aluno e dedicando atenção aos mais variados detalhes (como o acompanhamento do repertório desenvolvido pela banda) apontou para a necessidade de se buscar informações sobre registros (escritos ou fotos) da Banda ETFPEL que possibilitassem perceber as relações entre os estudantes e o instrumento que tocavam, a fim de que fosse possível compreender como se dava a distribuição dos instrumentos e se havia alguma mobilidade dos alunos em decorrência do tempo de ensaio ou de participação na Banda, bem como com relação ao seu amadurecimento e crescimento, considerando que muitos passavam anos como integrantes e poderiam, a partir das mudanças físicas típicas da adolescência, se tornarem aptos para instrumentos maiores ou mais pesados.

A dissertação "Prática de Banda em Escolas de Ensino Fundamental como Embasamento para Processo Pedagógico: um estudo de caso com duas escolas em Guarulhos - SP” (2014), de Athus Rogério Marconato, apresenta um estudo sobre duas escolas públicas municipais da cidade de Guarulhos, as quais receberam instrumentos musicais do governo para que se formassem bandas escolares. $\mathrm{O}$ autor cita o fato de que a maioria dos professores de música dessas escolas não aceitou aplicar atividades com os instrumentos de banda, levando a sua pesquisa a discutir a importância educativa das bandas escolares no início do século XXI.

A metodologia fundamentou-se na ciência de redes e na Abordagem Centrada na Pessoa e o estudo foi feito em duas escolas públicas, das quais o autor obteve dados para discussão da aplicabilidade e sucesso da prática de bandas com estudantes de Ensino Fundamental, apesar de concluir que a banda de escola possui origem e objetivos distintos dos da disciplina de educação musical.

$\mathrm{O}$ autor da pesquisa fala, a partir das filmagens que serviram de material para suas análises, sobre o que enxergou acerca da "Relação entre Ensino e Aprendizagem", detalhando as técnicas empregadas na harmonização da Banda Marcial de uma das escolas públicas estudadas, denominada EPG Castro Alves:

Foi constatada aprendizagem em rede, pois, no vídeo, ao longo da aula, pode-se observar os estudantes ajudando uns aos outros. Enquanto um trio tocava, os demais integrantes observavam, ajudavam a corrigir o alinhamento, a velocidade da marcha, e a regularidade no tempo da execução. Formaram-se aleatoriamente grupos que se espalharam pelas laterais da quadra, com algum natural dispersão, mas, em geral, participativos, agindo continuamente, preparando seus instrumentos, treinando passos ou assistindo à aula e esperando sua vez de marchar, enquanto um estudante segurava a câmera, que lhe foi confiada pelo professor (Marconato, 2014, p. 64).

Já em relação à escola Irmã Ofélia Echeverri Lopes, contrapondo-se à prática conservadora da escola EPG Castro Alves, o autor destaca o estilo popular e festivo que encontrou nessa Banda, fato que deixava seus integrantes mais leves e espontâneos ao executarem suas apresentações. Essa agremiação não contava com a austeridade da marcha, propiciando que os 
jovens dispensassem a atenção extrema ao posicionamento do corpo e se dedicassem mais à musicalidade, ao que estava sendo tocado.

Marconato (2014) expressa a vantagem da priorização à harmonia musical em detrimento da corporal e, sobretudo, ao repertório popular da Banda, que se aproximava muito mais do cotidiano da juventude, facilitando que os alunos encontrassem maior significado para sua aprendizagem.

Quanto à categoria "Motivação do Aluno", o autor reforça aquilo que enxergou na importância corporativa do ambiente de uma Banda Marcial, reforçando os laços afetivos e sociais dos jovens, onde "os músicos mais experientes ajudam os mais novos em suas dificuldades, vários alunos unem-se voluntariamente para estudar, formando grupos de aprendizado mútuo, pessoas agem em rede para obter sucesso nos concertos e concursos” (Marconato, 2014, p. 35).

É característica das bandas em geral, que, por ocasião de um concurso, amigos e membros das famílias dos alunos disponham-se a realizar o apoio técnico, organizando acomodações nos ônibus, realizando entrega dos lanches, e fazendo reparos emergenciais nos uniformes. É fácil identificar a movimentação dos voluntários. São mães que portam garrafas com água, pessoas que correm com estantes para partituras, enquanto outros costuram botões que caem de uniformes, lustram ornamentos, etc (Marconato, 2014, p. 35 - 36).

O autor reforça que tais laços afetivos e sociais são extensivos às famílias dos integrantes da Banda, que inserem-se no universo marcial e ampliam o vínculo interfamiliar, criando uma rede de colaboração. No excerto acima, percebe-se que um dos fatores que pode ser atrelado à motivação do aluno se refere, possivelmente, à possibilidade de proporcionar lazer e integração aos seus familiares.

Dentre as contribuições desta dissertação para a pesquisa que seria feita sobre a Banda ETFPEL, as temáticas do envolvimento familiar e do processo de aprendizagem em rede dos alunos foram pontos que chamaram bastante a atenção - os quais os entrevistados, posteriormente, ressaltaram, ao falarem das suas vivências pessoais.

A tese "Saberes Percussivos nas Escolas Públicas da cidade de Fortaleza" (2017), de autoria de Catherine Furtado dos Santos, teve por objetivo analisar os saberes percussivos produzidos pelos grupos de Maracatus e Banda Marcial-Show nas escolas públicas da cidade de Fortaleza. No espaço escolar, a partir das literaturas na área e dos dados empíricos coletados através da pesquisa de campo, a autora identifica que as práticas percussivas em coletivo são desenvolvidas, principalmente, por grupos de maracatus e fanfarras, constituindo-se como grupos de atividades extracurriculares que realizam ensaios, atividades e apresentações artísticas. Tal fenômeno propiciou a problematização sobre a existência desses grupos como geradores de conhecimento, mesmo sem uma articulação com as atividades educativas da escola.

Diante desse conjunto de práticas na realidade escolar, a pesquisa afirma a existência dos saberes percussivos através das dimensões educativas do saber epistêmico, de identidade e social com base na teoria da relação com o saber ${ }^{3}$, e propõe uma reflexão nos termos das epistemologias do $\mathrm{sul}^{4}$, para uma possibilidade educacional construtiva e válida a partir das práticas percussivas em coletivo nas escolas públicas. A partir de entrevistas semiabertas - com os sujeitos escolhidos - a pesquisa identificou as práticas percussivas desenvolvidas e compreendeu os sentidos atribuídos pelos sujeitos nesse processo de aprendizagem. Assim, o trabalho busca trazer contribuições ao campo da educação musical a partir de uma perspectiva socioeducativa no contexto do espaço escolar, uma vez que trata da importância da musicalização nas escolas, com toda a bagagem cultural que trazem à tona, difundindo o acesso do jovem de escola pública aos saberes musicais.

\footnotetext{
${ }^{3}$ Termo relevante em diversas obras de Bernard Charlot, que teoriza sobre diversos aspectos da escola, o saber e o sujeito que aprende. Como leitura sobre a temática, indica-se Da relação do saber com as práticas educativas (Editora Cortez, 2013) e Relação com o saber: formação de professores e globalização (Artmed, 2005).

${ }^{4}$ Termo relevante nos estudos de Boaventura de Souza Santos, o qual remete à descolonização dos saberes propagados e legitimados. Como leitura sobre a temática, indica-se Epistemologias do Sul (2009), organizado por Boaventura de Souza Santos e Maria Paula Menses (Edições Almedina).
} 
Uma leitura atenta do trabalho de Santos (2010) possibilita perceber que os campeonatos de Bandas Marciais eram mecanismos que agregavam a comunidade escolar e que entusiasmavam seus pertencentes. Apesar disso, em função do objetivo específico das bandas apresentarem-se nos desfiles cívicos de setembro, o projeto musical é desarticulado:

As escolas pedem a formação de fanfarras por causa dos desfiles do 7 de setembro. Isso é muito o que a direção de uma escola quer, mas as Bandas têm prazo de validade. As bandas começam em janeiro e terminam no 7 de setembro. Aí a escola fala: "Quero mais não... dá muita dor de cabeça” (Ítalo apud Santos, 2017, p. 87).

Neste excerto, relacionado com a categoria "Relação entre Ensino e Aprendizagem", a pesquisadora sublinha que, por falta de continuidade, as Bandas acabam por comprometer sua evolução no processo de aprimoramento musical, uma vez que faltam incentivos e investimentos neste tipo de educação artística, conforme o entrevistado acima dispõe.

No que tange à prática do ensino e aprendizagem abordada no espaço da Banda Marcial, o Regente da Banda Solares, que também era professor de música da grade curricular de outras escolas, salienta que a oportunidade dada a ele para reger a agremiação incentivou-o a refletir sobre a sua didática em sala de aula e o incentivou a buscar mais estudos específicos da área de regência em bandas.

Diferente dos métodos tradicionais a gente não prefere a teoria antes da prática. Então assim logo no início eu já os coloco para praticarem porque alguns meninos já se encantam logo quando a gente começa a tocar e se você coloca a teoria eles se desencantam e se travam. Então a gente já coloca o instrumento na mão. Como é que toca? Como é que sopra? É assim! Aí com o tempo a gente vai caminhando. É tanto que essa nova safra que tá vindo agora já tá começando a ler partitura. Eu coloco primeiro pra tocar, mas aí eu digo: Pronto, esse aqui é o Dó. Fica no espaço tal da partitura. E a partir daí fica vindo à prática e a teoria juntos" (Augusto apud Santos, 2017, p. 88).

Ao destacar em sua pesquisa o trecho anterior, Santos (2017) dispõe sobre a importância, para a história daquela banda, de começar os estudos musicais, em grupo, através da prática e não, como antes, pela exclusividade na teoria musical. Há com isso a avaliação de que é preciso aproveitar as habilidades já trazidas e existentes em cada sujeito ingressante na turma para aprender.

Quanto à categoria "Motivação do Aluno", salienta-se um excerto da tese que diz: "O motivo de esses meninos estarem aqui são as competições. É mostrar o trabalho deles na frente de outra banda e dizer que nós somos os melhores. É isso que move ele". (Pinheiro apud Santos, 2017, p. 86). Por esta declaração, Santos (2017) dá destaque ao efeito de inclusão social que a Banda promovia em seus integrantes, segundo o entrevistado, uma vez que os campeonatos de Bandas movimentavam socialmente os alunos da escola, em sua maioria de baixa renda, que viam na agremiação musical uma oportunidade de aparecer para toda a população da região em que viviam, colocando em evidência tudo aquilo que aprendiam, em busca de vencer e obter destaque perante as Bandas Marciais rivais. Esta tese reforçou a necessidade de estar atento, no fazer da pesquisa sobre a Banda ETFPEL, às competições de banda, que ainda não lembradas no imaginário da cidade de Pelotas. ${ }^{5}$

A releitura desses quatro trabalhos possibilitou, como comentado anteriormente, uma atividade de síntese, que levou à elaboração das categorias Relação entre Ensino e Aprendizagem e Motivação do Aluno. Todavia, as citações aqui reproduzidas permitem que se as olhe mais detalhadamente, não como um exercício puramente classificatório para se criar subcategorias, mas também como um processo que pretende entender quais partes - quais elementos, quais vivências - se articulam e dão forma àqueles espaços.

Considerando isso, foram elaborados dois fluxogramas, referentes às duas categorias elencadas, as quais emergiram da revisitação dos textos do Estado do Conhecimento. Eles ilustram, em palavras-chave, subcategorias para serem cotejadas com as entrevistas transcritas por Velasco (2019) na elaboração da sua dissertação sobre uma historiografia da Banda ETPEL.

\footnotetext{
${ }^{5}$ Faz parte, de certo modo, da história de Pelotas e da história da ETFPEL os campeonatos de bandas escolares. Esses, que ainda hoje impregnam a memória de muitos habitantes da cidade, foi uma das motivações iniciais para que fosse pensada uma dissertação sobre a Banda Marcial ETFPEL, agremiação bicampeã nacional (1987 e 1988) e seis vezes campeã estadual (1967, 1968, 1970,1999, 2000 e 2001).
} 
Ressalta-se, contudo, que elas não são um molde a ser forçosamente preenchido pelos estudos feitos por Velasco (2019), mas que subsidiam uma interpretação sobre espaços comuns e dissonantes relatados pelos ex-membros da Banda ETFPEL, a partir de suas vivências e memórias.

Figura 1 - Fluxogramas das categorias "Relação entre Ensino e Aprendizagem" e "Motivação do Aluno".
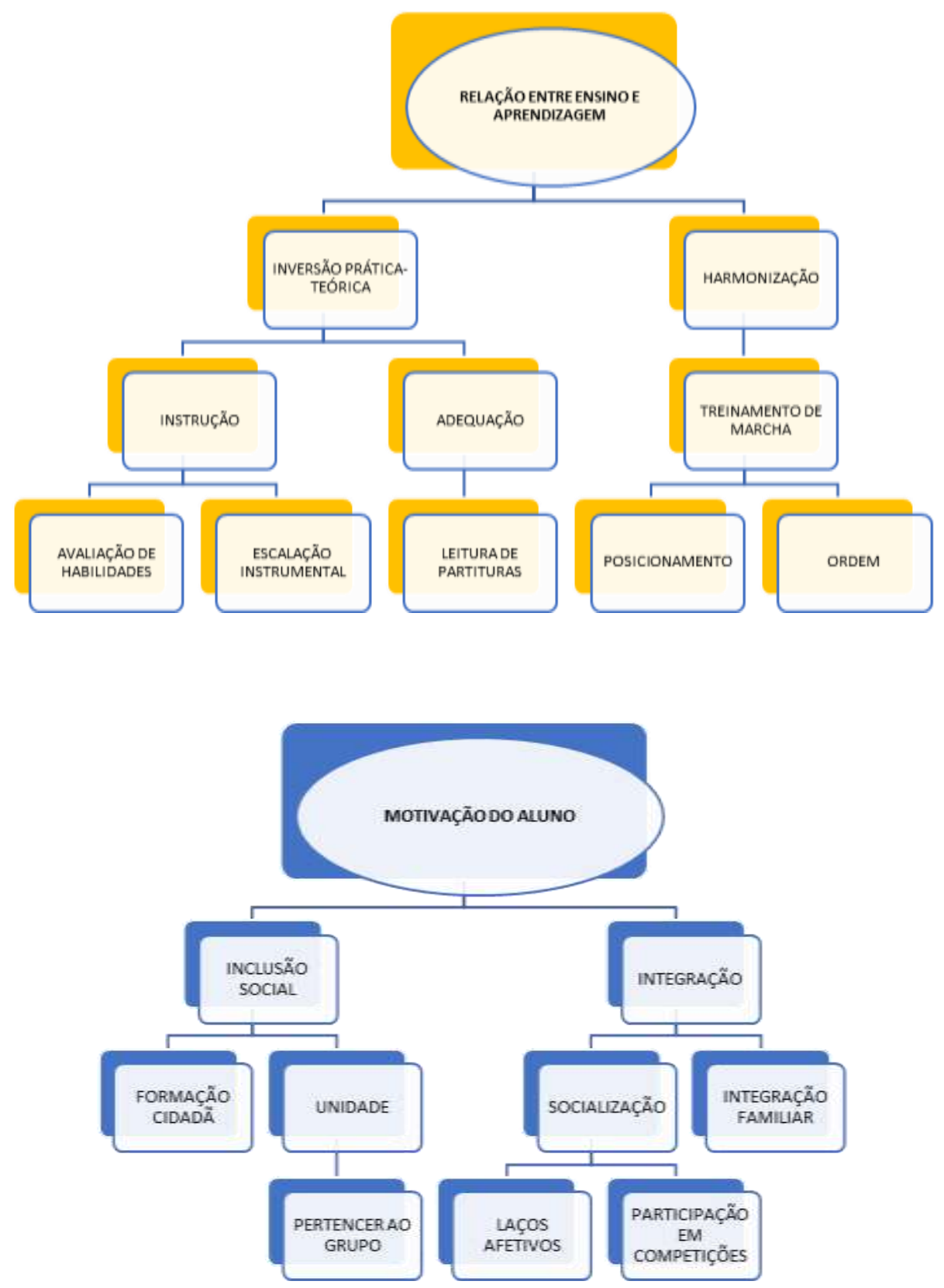

Fonte: Autores (2021).

Os fluxogramas revelam pontos de atenção: é importante salientar que a maioria das subcategorias parece não ser acessível à pesquisa pelo manuseio das fontes mais comuns, tais como documentos escritos (inventário dos instrumentos, matérias em jornais, atas da instituição etc) ou fotos. A percepção dessas singularidades é central para que se abra uma discussão acerca da História Oral (HO) enquanto metodologia de pesquisa, a qual tem algumas particularidades com relação a outras formas de se utilizar a entrevista como coleta de dados para uma pesquisa qualitativa. 
A HO foi utilizada por Velasco (2019) na produção da sua dissertação, que assumiu suas concepções ao longo da pesquisa, desde a elaboração do roteiro de entrevista à disponibilização das transcrições, sendo todo o processo autorizado pelos entrevistados.

\section{História Oral: Produção e Análise das Entrevistas do Ex-Membros da Banda ETFPEL}

Como destaca Freitas (2003), o que existe, sem fontes, é apenas uma história criada pela imaginação, motivo pelo qual é o manuseio das fontes documentais utilizadas pelo pesquisador que vem corroborar - ou esfacelar - as hipóteses que o pesquisador histórico investiga, ou seja, os resultados da pesquisa devem decorrer das relações estabelecidas entre as fontes e a historiografia.

Na busca por compreender melhor a elaboração, o tratamento e a importância das entrevistas para o fazer da pesquisa, visando aproximar-se dos processos de ensino e aprendizagem dentro das Bandas Marciais Escolares brasileiras, foi utilizada a História Oral enquanto metodologia de pesquisa qualitativa, dando-lhe centralidade ao processo que, obviamente, não abriu mão das demais fontes documentais.

A opção por utilizar entrevistas com os alunos que pertenceram à Banda ETFPEL pautou-se na intenção de tentar olhar para a temática da juventude, buscando entender a carga cultural das percepções dos ex-integrantes acerca do "fazer parte" de uma comunidade musical, tendo a ciência de que

Trabalhar sobre relatos de "história de vida" no campo das ciências é uma revolução metodológica que constitui emergência de dois paradigmas: o paradigma de um conhecimento fundamentado sobre uma subjetividade explicitada e o paradigma de um conhecimento experiencial que valoriza a reflexividade produzida a partir de vivências singulares (Bianco \& Bohland Filho, 2020, p. 3).

Nem sempre as fontes orais foram aceitas como documento histórico. Para que se pudesse repensar o papel destas fontes, foi preciso que o historiador francês Marc Bloch, somado à renomada Escola dos Annales ${ }^{6}$, entidade de que foi um dos fundadores, investisse na defesa de uma perspectiva que considerasse a ampliação da noção de documento histórico. O resultado - obviamente não a curto prazo, como aqui rapidamente se aponta - foi a quebra de paradigmas, sobretudo na forma de lidar com as fontes existentes, o que produziu críticas à visão mais tradicional de documento, o chamado “documento oficial”, como fonte histórica única e soberana.

Bloch (1965, p. 220) dispõe: “O documento não é apenas a fonte, é o problema”. Sendo assim, o autor defendeu que a escassez de registros escritos como documentos históricos não podia representar a ausência de possibilidade de escrever a História. Neste contexto, o conceito de documento em seu sentido mais amplo foi alargado para além dos textos e registros tradicionais. Um bom tempo depois, Le Goff (1990), nesta perspectiva, destacou que tudo o que diz respeito ao homem pode ser disposto como fonte histórica e, em vista disso, deve ser considerado como documento.

A HO é um recurso de perspectiva teórico-metodológica utilizado em pesquisas qualitativas. Muito embora Thompson (1992) afirme que a HO seja tão antiga quanto a própria História, como metodologia historiográfica obteve seu marco de criação após a segunda guerra mundial, nos Estados Unidos, quando a invenção dos gravadores possibilitou que se "armazenassem" discursos orais. Sendo assim, a HO permite "que se recrie a multiplicidade original de pontos de vista" (Thompson, 1992, p. 25-26), pois comumente escuta a narrativa de diferentes pessoas envolvidas num mesmo acontecimento.

\footnotetext{
${ }^{6}$ Movimento historiográfico surgido na França, durante a primeira metade do século XX, que conquistou grande evolução dos métodos de se escrever e pensar sobre História. A historiografia passou por grandes modificações metodológicas que permitiram maior conhecimento do cotidiano do passado, através da incorporação de novos tipos de fontes de pesquisa. (Barros, 2010).
} 
No decorrer do tempo, a partir da segunda metade do século XX, a HO teve por propósito "dar voz aos excluídos" (Fiorucci, 2010, p. 7), muito embora esta expressão já tenha sido superada, já que é possível fazer HO com pessoas mudas, por exemplo, cuja “voz" é expressa de outro modo, por outras linguagens.

Em suma, a HO é uma metodologia utilizada para produzir fontes que possibilitem elaborar e apresentar uma historiografia de um tempo passado, mas relativamente recente, nos dias atuais. Garnica (2003) explica que a HO é um tipo de metodologia de pesquisa que envolve a coleta de dados através de depoimentos de pessoas que fizeram parte de algum momento histórico que se quer analisar; à análise dos depoimentos, feitas a posteriori, podem ser aplicadas diferentes metodologias de interpretação de dados. Nessa perspectiva, a HO permite trabalhar com distintas narrativas de um mesmo acontecimento.

Ainda, a HO valoriza a questão subjetiva, pois os dados objetivos podem ser procurados em documentos de uma maneira geral, mas a subjetividade intrínseca à narrativa - que era um ponto de forte interesse na pesquisa sobre a Banda ETFPEL - é, de certa forma, a contribuição que a HO pode apresentar como diferencial metodológico, caso o entrevistador esteja preparado para percebê-la nas falas e no comportamento do entrevistado.

Nessas condições, Portelli (2016) afirma que só há troca se há diferença: existem estímulos imprevistos por parte do entrevistado, em relação ao entrevistador, quando o primeiro explora aspectos de sua experiência que geralmente não são mencionados quando expostos ao seu círculo social imediato, muitas vezes deixando sua zona de conforto ao aderir à proposta historiográfica sugerida pelo pesquisador - tem-se, aí, um processo de cocriação de fontes orais, que são as fontes para a pesquisa surgidas a partir deste diálogo. As fontes orais não são encontradas e sim geradas em uma troca dialética - de palavras e de olhares, literalmente. Mesmo quando o diálogo permanece dentro da agenda original, é comum que a informação mais importante se encontre para além daquilo que tanto o historiador quanto o narrador consideram historicamente relevante.

Portelli (2010, p. 186) considera a HO "uma oportunidade para narradores relativamente obscuros serem canonizados no discurso público: um relato público realizado por pessoas que raramente têm a oportunidade de falar publicamente", afirmação que se mostra verdadeira neste caso em virtude de que não havia sido produzida uma historiografia da Banda ETFPEL, a partir da conversa com alguns de seus ex-membros, até Velasco (2019) publicar seu trabalho.

Na dissertação Recordações em pauta: uma narrativa sobre a banda marcial da Escola Técnica Federal de Pelotas (ETFPEL) entre as décadas de 60 e 70, as entrevistas, juntamente com outras fontes, possibilitaram que se escrevesse uma historiografia da banda pautada em dois pilares: sua existência e a conquista do seu maior título (o Tricampeonato Estadual de Bandas Marciais, conquistado em Porto Alegre, em 1970).

Neste artigo, a releitura das entrevistas possibilitou aproximar a experiência dos ex-membros da Banda ETFPEL àquelas vividas por outros alunos, em outras localidades e temporalidades, nas bandas cujos trabalhos foram comentados na seção anterior. Suas falas ressaltam as subcategorias que, dos fluxogramas da Figura 1, permanecem na elaboração da Figura 2. 
Figura 2 - Fluxogramas das categorias "Relação entre Ensino e Aprendizagem" e "Motivação do Aluno", construído a partir das entrevistas dos ex-membros da Banda EFPEL.
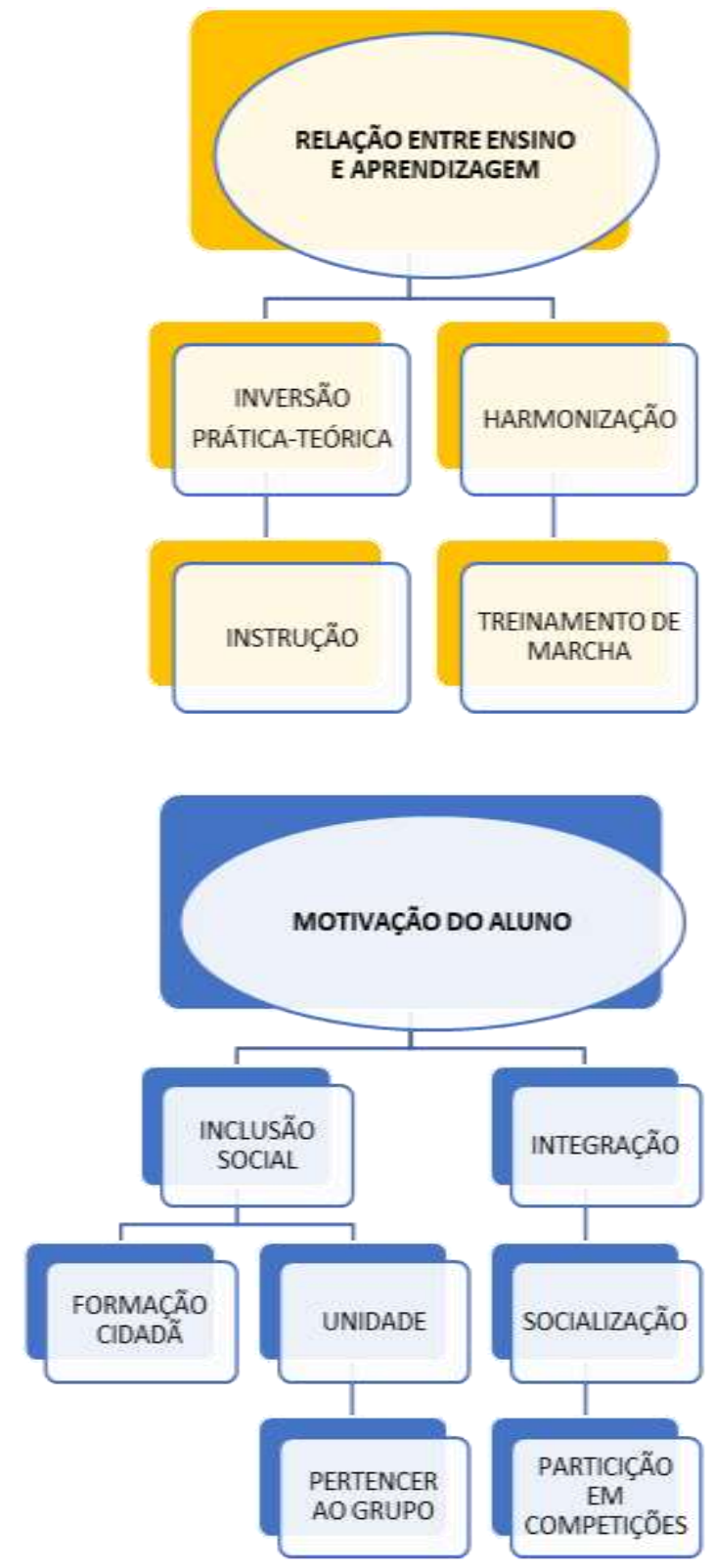

Fonte: Autores (2021).

A transcrição completa das entrevistas deu origem a um livreto ${ }^{7}$, motivo pelo qual as falas dos entrevistados não serão aqui retomadas com riqueza de detalhes.

Contudo, elas possibilitaram perceber que a Banda ETFPEL tinha um sistema de ensino que também privilegiava a prática como instrução, como conta Cunha (apud Velasco, 2019), ao recordar que aprendeu a tocar pistão depois que o professor escreveu o número dos pistons nas notas da música, e Rezende (apud Velasco, 2019), que se lembra de participar de ensaios quase que diários, mas não faz qualquer menção à leitura de partituras.

Questões como a harmonização e o treinamento de marcha eram características da Banda ETFPEL por ela ser marcial. Rezende (apud Velasco, 2019) é um dos entrevistados que cita o "passo de ganso", modo como os membros da banda caminhavam, com passadas grandes em que o joelho se erguia até fazer ângulo reto com a perna, antes de colocar o pé no chão

${ }^{7}$ Além das transcrições, o livreto é constituído de fotos e de uma pequena apresentação de cada entrevistado. Este material está disponível no endereço http://educapes.capes.gov.br/handle/capes/574025 
novamente. A harmonização era importante e, para alcançarem-na, os membros da banda costumavam sair da escola em marcha pelas ruas da cidade (Moura apud Velasco, 2019), pois sabiam que este era um dos quesitos de avaliação nos campeonatos dos quais tomavam parte.

Com relação à motivação, todos os entrevistados a citam, por diferentes recordações: a banda era um espaço de promoção social que levava os estudantes a outras cidades, não só para competições como também para apresentações, e seu reconhecimento em Pelotas fazia com que houvesse lista de espera de alunos da instituição que queriam tomar parte nela (Rezende apud Velasco, 2019). A questão de se sentirem parte de um grupo e a convivência de longo prazo deixou marcas de amizade nos ex-integrantes, que até hoje se encontram sempre que possível, e reconhecem que a disciplina que aprenderam naquele espaço foi fundamental para suas vivências cidadãs na idade adulta e para sua integração à sociedade, sobretudo como trabalhadores e pais de família (Rezende; Renck apud Velasco, 2019).

\section{Considerações Finais}

O Estado do Conhecimento, por fazer referência ao que já se tem exposto sobre o assunto pesquisado, é uma importante ferramenta para se constituir um trabalho científico, auxiliando na tomada de decisões e escolha de percursos. Trata-se de uma atividade árdua por ser crítica e reflexiva, mas de um grande teor agregado de conteúdo que facilita, e muito, o desenvolvimento do trabalho acadêmico.

O propósito com este texto foi, em um primeiro momento, instrumentalizar leitores e/ou pesquisadores interessados na temática das bandas escolares, a partir da partilha das pesquisas encontradas, as quais podem servir para subsidiar a fundamentação teórica e apresentar os procedimentos metodológicos a serem adotados em novas pesquisas; num segundo momento, foi apresentar a produção de uma síntese dos textos elencados no Estado do Conhecimento como um exercício que visava compreender melhor o narrado pelos depoentes que tomaram parte naquelas pesquisas, a fim de se desenhar um cenário das experiências pedagógicas vivenciadas pelos estudantes que integram uma banda escolar.

A partir dessa síntese, posteriormente comparada com as transcrições da pesquisa produzida por Velasco (2019), é possível concluir que a maioria dos jovens pertencentes a estes espaços considera que o fato de fazer parte de uma Banda influencia suas vidas dentro e fora da escola, por meio de uma prática de inclusão social que lhes possibilita frequentar um ambiente de aprendizado musical. Ainda, questões como turismo, integração, saúde mental, satisfação pessoal em evoluir em conjunto, rotina lúdica, unidade, espírito de equipe etc, estão, em maior ou menor escola, associadas à participação na banda escolar, o que demonstra que, nas comunidades em que estes estudos foram realizados, pertencer a uma Banda Marcial traduzse em boas e importantes vivências na comunidade escolar.

Todavia, se faz importante apresentar um contraponto: entende-se que nem todos os trabalhos concordam inteiramente que tais práticas marciais de ensino nas Bandas fomentam agradável inclusão social a quem está em seu ambiente, o que se percebe dos relatos trazidos por Marconato (2014), quando expõe que o Regente da Banda preocupava-se demasiadamente com a marcha dos músicos - ao priorizar certos aspectos da marcialidade, tais como precisão, disciplina, atenção, concentração nos movimentos do corpo em acordo com o som tocado e observação ao alinhamento e velocidade do passo, o pesquisador sublinha que a aula fica envolta numa certa rigidez. Além disso, embora concorde que as bandas marciais ajudam a desenvolver um espírito de conjunto, entende que tais práticas "podem não ser favoráveis, na hipótese de haver alguém que seja constantemente preso e submetido a regras excessivas - em casa, na sala de aula, na prática religiosa, etc” (Marconato, 2014, p. 64). Desta forma, o autor entende que o ambiente marcial, ao invés de inserir o jovem em um espaço de integração, pode estar reprimindo-o por motivos alheios à Banda, devido suas experiências negativas com este tipo de comportamento rígido. 
Considerando as particularidades da instituição pesquisada por Velasco (2019), no que tange à Banda ETFPEL, algumas temáticas mostram maior ou menor convergência com o que o Estado do Conhecimento ajudou a produzir enquanto síntese. Deste modo, percebe-se que, destarte as localidades e épocas diferentes, algumas vivências são comuns para os integrantes da Banda ETFPEL e das demais, sobretudo o fato de, nas bandas, o método de aprendizagem ser uma inversão da aula tradicional (começando pela prática e, muitas vezes, nem chegando à teoria da música) e de a motivação do aluno estar associada a uma atividade que, mesmo que tenha sede dentro da escola, é vista fora dela. Talvez estes dois pontos - inversão prática-teórica e atividades extramuros - sejam temáticas que as bandas escolares podem ajudar a pensar, a fim de que sejam estendidos para outras práticas que acontecem na escola.

Este artigo - que, como dito, revisita a dissertação já defendida de Velasco (2019) - traz a possibilidade de se dirigir novos olhares interpretativos para o passado, considerando que a Banda Marcial ETFPel não existe mais; a partir do conjunto formado pelas reflexões expressas neste texto, pelos olhares que a pesquisa suscitou e com a participação dos entrevistados, deseja-se organizar uma exposição no saguão da instituição, a qual constantemente faz resgates da sua história. Tal intento foi suspenso por conta da epidemia de COVID-19, mas será retomado tão logo possa, tanto como espaço de interação quanto como de observação para a coleta de dados para novas pesquisas.

\section{Referências}

Bianco, M. F., \& Bohland Filho, J. (2020). História Oral e Sujeito Reflexivo: aspectos epistemológicos, conceituais e práticos. Research, Society and Development, 9 (10). https://rsdjournal.org/index.php/rsd/article/view/9105/8108. http://dx.doi.org/10.33448/rsd-v9i10.9105.

Bloch, M. (1965). Introdução a História: Europa-América.

Brandani, N. (1985). A banda Marcial como Núcleo de Educação Musical. [Dissertação de Mestrado, Universidade de São Paulo]. Biblioteca de Teses e Dissertações. https://repositorio.usp.br/item/000731838.

Charlot, B. (2000). Da relação com o saber: elementos para uma teoria: Artmed

Ferreira, M. de M. (2002). História, tempo presente e história oral. Revista Topoi, 3 (5), 314-332. 10.1590/2237-101X003006013.

Fiorucci, R. (2010). História oral, memória, História. In: Revista História em Reflexão, 4 (8), 1-17. https://ojs.ufgd.edu.br/index.ph p/historiaemreflexao/article/view/952/587.

Flick, U. (2009). Qualidade na pesquisa qualitativa: Artmed.

Freitas, S. M. (2003). História oral: possibilidades e procedimentos: Humanitas.

Garnica, A. V. M., \& Souza, L. A. (2003). História Oral e Educação Matemática: de um inventário a uma regularização. Zetetiké, 11 (19), 9-56. 10.20396/zet.v11i19.8646949.

Gunther, H. (2006). Pesquisa qualitativa versus pesquisa quantitativa: esta é uma questão? Psicologia: Teoria e Pesquisa, 22 (2), 201-209. 10.1590/S010237722006000200010 .

Le Goff, J. (1990). História e memória: Editora da Unicamp.

Lehfeld, N. A. S., \& Barros, A. J. P. (1991). Projeto de pesquisa: propostas metodológicas: Vozes.

Marconato, A. R. (2014). Prática de banda em escolas de ensino fundamental como embasamento para processo pedagógico: um estudo de caso com duas escolas em Guarulhos-SP. [Dissertação de Mestrado, Universidade Estadual Paulista Julio de Mesquita Filho]. Biblioteca de Teses e Dissertações. https://repositorio.unesp.br/handle/11449/115714.

Pereira, A. S., Shitsuka, D. M., Parreira, F. J., \& Shitsuka, R. (2018). Metodologia da pesquisa científica. [e-book]. Santa Maria. Ed. UAB/NTE/UFSM. https://www.ufsm.br/app/uploads/sites/358/2019/02/Metodologia-da-Pesquisa-Cientifica_final.pdf.

Portelli, A. (2010). Ensaios de História Oral: Letra e Voz.

Portelli, A. (2016). História oral como arte da escuta: Letra e Voz.

Santos, C. F. (2017). Saberes percussivos nas escolas públicas da cidade de Fortaleza. [Tese de Doutorado, Universidade Federal do Ceará]. Biblioteca de Teses e Dissertações. http://www.repositorio.ufc.br/handle/riufc/24234.

Silva, T. B. (2012) Banda Marcial Augusto dos Anjos: processos de ensino aprendizagem musical. [Dissertação de Mestrado, Universidade Federal da Paraíba]. Biblioteca de Teses e Dissertações. https://repositorio.ufpb.br/jspui/handle/tede/6595. 
Research, Society and Development, v. 10, n. 2, e55310212892, 2021

(CC BY 4.0) | ISSN 2525-3409 | DOI: http://dx.doi.org/10.33448/rsd-v10i2.12892

Souza, E. de L. (2010). "P'rá ver a banda passar": uma etnografia musical da Banda Marcial Castro Alves. [Dissertação de Mestrado, Universidade Federal da Paraíba]. Biblioteca de Teses e Dissertações. https://repositorio.ufpb.br/jspui/handle/tede/8757.

Teixeira, P. M. M. (Org.). (2017). A produção acadêmica em ensino de Biologia no Brasil - 40 anos (1972 - 2011): base institucional e tendências temáticas e metodológicas. Revista Brasileira de Pesquisa em Educação em Ciências, 17 (2), 521-549. 10.28976/1984-2686rbpec2017172521.

Thompson, P. (1992). A voz do passado: história oral: Paz e Terra.

Velasco, R. de S. (2020). Entrevistas: recordações em pauta: uma narrativa sobre a Banda Marcial da Escola Técnica Federal de Pelotas (ETFPEL) entre as décadas de 60 e 70: IFSul. http://educapes.capes.gov.br/handle/capes/574025.

Velasco, R. de S. (2019). Recordações em pauta: uma narrativa sobre a Banda Marcial da Escola Técnica Federal de Pelotas (ETFPEL) entre as décadas de $60 e$ 70. [Dissertação de Mestrado, Instituto Federal Sul-Rio-Grandense]. Biblioteca de Teses e Dissertações. http://omp.ifsul.edu.br/index.php/repositorioinstitucional/catalog/book/167. 